\title{
Systematic review and meta-analysis of cardiac involvement in mitochondrial myopathy
}

Asfia Quadir, Carly Sabine Pontifex, BSc, Helen Lee Robertson, MLIS, Christopher Labos, MD, MSc, and Gerald Pfeffer, MD, PhD

Neurol Genet 2019;5:e339. doi:10.1212/NXG.0000000000000339

\author{
Correspondence \\ Dr. Pfeffer \\ gerald.pfeffer@ucalgary.ca
}

\section{Abstract}

\section{Objective}

Our goal was to perform a systematic review of the literature to demonstrate the prevalence of cardiac abnormalities identified using cardiac investigations in patients with mitochondrial myopathy (MM).

\section{Methods}

This systematic review surveys the available evidence for cardiac investigations in MM from a total of 21 studies including 825 participants. Data were stratified by genetic mutation and clinical syndrome.

\section{Results}

We identified echocardiogram and ECG as the principal screening modalities that identify cardiac structural (29\%) and conduction abnormalities (39\%) in various MM syndromes. ECG abnormalities were more prevalent in patients with m.3243A $>\mathrm{G}$ mutations than other gene defects, and patients with mitochondrial encephalopathy, lactic acidosis, and stroke-like episodes (MELAS) had a higher prevalence of ECG abnormalities than patients with other clinical syndromes. Echocardiogram abnormalities were significantly more prevalent in patients with m.3243A $>$ G or m.8344A $>$ G mutations compared with other genetic mutations. Similarly, MELAS and MERRF had a higher prevalence compared with other syndromes. We observed a descriptive finding of an increased prevalence of ECG abnormalities in pediatric patients compared with adults.

\section{Conclusions}

This analysis supports the presence of a more severe cardiac phenotype in MELAS and myoclonic epilepsy with ragged red fibres syndromes and with their commonly associated genetic mutations (m.3243A $>\mathrm{G}$ and $\mathrm{m} .8344 \mathrm{~A}>\mathrm{G}$ ). This provides the first evidence basis on which to provide more intensive cardiac screening for patients with certain clinical syndromes and genetic mutations. However, the data are based on a small number of studies. We recommend further studies of natural history, therapeutic response, pediatric participants, and cardiac MRI as areas for future investigation.

\footnotetext{
From the Hotchkiss Brain Institute (A.Q., C.S.P., G.P.), University of Calgary; Health Sciences Library (H.L.R.), University of Calgary, Alberta; Queen Elizabeth Health Complex (C.L.), Montreal, Quebec; and Department of Clinical Neurosciences (G.P.), Cumming School of Medicine, University of Calgary, Alberta, Canada. 


\section{Glossary}

BBB = bundle branch block; $\mathbf{C I}=$ confidence interval; $\mathbf{C M R}=$ cardiac MRI; CPEO = chronic progressive external ophthalmoplegia; KSS = Kearns-Sayre syndrome; LVH = left ventricular hypertrophy; MELAS = mitochondrial encephalopathy, lactic acidosis, and stroke-like episodes; MERRF = myoclonic epilepsy with ragged red fibres; $\mathbf{M M}=$ mitochondrial myopathy; mtDNA = mitochondrial DNA; WPW = Wolff-Parkinson-White syndrome.

Mitochondrial myopathies (MMs) are clinically heterogeneous disorders resulting from defects in the respiratory chain, preferentially affecting organs with high-energy requirements. Cardiac dysfunction is common as part of the phenotype of MM and is manifested by cardiomyopathy, cardiac conduction defects, and/or heart failure. ${ }^{1}$ The identification of cardiac dysfunction is particularly important because of its impact on quality of life, morbidity, mortality, and especially because it is amenable to treatment. ${ }^{2}$ Some mitochondrial syndromes, such as Kearns-Sayre syndrome (KSS) include cardiac dysfunction as a core feature. ${ }^{2}$ However, most of the common mitochondrial syndromes may or may not include cardiac dysfunction, which can occur at any point in the disease course, and as such screening investigations are recommended for early detection. At present, the optimal investigations and time intervals for screening are not established, and studies describing the natural history of cardiac dysfunction in MM have been limited. ${ }^{3}$

This systematic review serves to summarize the available evidence regarding screening investigations to: (1) provide data indicating the diagnostic yield of different cardiac investigations, (2) compare the frequency of cardiac abnormalities in differing mitochondrial syndromes and genotypes, (3) compare the frequency of diagnostic abnormalities between pediatric and adult patients, and (4) identify limitations in the evidence and areas for future study. The overall goal of this study is to systematically demonstrate the prevalence of cardiac abnormalities across various MM syndromes.

\section{Methods}

Two investigators (A.Q. and G.P.) created a preliminary search strategy that was subsequently refined by a medical librarian (H.L.R.). The search was conducted on June 4, 2018, on the following databases: Epub Ahead of Print, In-Process \& Other Non-Indexed Citations, Ovid MEDLINE Daily and Ovid MEDLINE, EMBASE, Cochrane Central Register of Controlled Trials, Scopus, and Web of Science. Combinations of subject headings, keywords, and synonyms used included MMs, mitochondrial encephalomyopathies, Kearns-Sayre Syndrome, cardiomyopathy, cardiac arrhythmia, and tachycardia. Full search terms are available in supplemental data (links.lww.com/ NXG/A159). The authors (A.Q. and G.P.) independently screened all titles and abstracts identified by the initial search. We obtained full-text versions of studies identified as being potentially relevant, which were then independently assessed. Only English-language publications were considered.
We also performed a search through the bibliographies of all included articles to ensure that no other relevant articles were missed, although no additional publications for inclusion were identified by these means.

\section{Study selection}

We included all studies in which patients had a confirmed diagnosis of MM using genetic testing and/or muscle pathology. We did not include patients with KSS because this syndrome includes cardiac dysfunction as a core feature of its diagnostic criteria. Our objective was to identify all published studies documenting cardiac complications of MM and using at least one modality of cardiac investigation. Studies that did not disclose the investigative modality or presented focused or incomplete data were not included. Cross-sectional studies, cohort studies, or clinical trials were included in our review. Case reports (i.e., small studies of 4 or fewer cases) were excluded.

\section{Data extraction}

Data extraction was independently performed by 2 of the authors (A.Q. and C.S.P.), using a custom-designed data extraction form, which was piloted on 5 randomly selected eligible studies before being finalized. In cases of disagreement, 3 of the authors (A.Q., C.S.P., and G.P.) discussed the discrepancies to reach a consensus.

The information extracted included year of study, duration of follow-up, number of participants, age, the diagnostic tests used, the number of subjects with abnormal results with ECG, echocardiography (echo), Holter monitor, cardiac MRI (CMRI), and nuclear medicine studies. We also collected data regarding treatment and clinical outcomes where available. When data were incomplete, we attempted to contact authors of the relevant articles to obtain more detailed data and received such data for 2 publications. ${ }^{4,5}$

For purposes of our analysis, data from child (aged $<18$ years) and adult (aged $\geq 18$ years) patients were recorded and analyzed separately. Adult patients who had disease onset in childhood were still included in the adult group. Data were stratified using 2 separate approaches: based on genetic subtypes of $\mathrm{MM}$ (m.3243A $>\mathrm{G}$ mutation, m.8344A $>\mathrm{G}$ mutation, other mitochondrial DNA (mtDNA) point mutations, single large-scale mtDNA deletions, and nuclear gene mutations) and based on clinical syndromes (mitochondrial encephalopathy, lactic acidosis, and stroke-like episodes [MELAS], chronic progressive external ophthalmoplegia [CPEO] or other phenotypes of MM). Clinical syndromes were defined based on how they had been identified within individual 
articles. In cases in which the specific syndrome was not defined but the genotype was available, if sufficient individualized data were presented, we would infer the clinical syndrome for individual patients (e.g., a patient with the m.3243A $>$ G mutation with stroke-like episodes, encephalopathy, and lactic acidosis would be interpreted as a MELAS syndrome case). Patients with unspecified syndromes were included in a category labeled "other phenotypes."

Based on this approach, we allowed cases to be counted in both the genetic group and the clinical syndrome group if individualized data were reported for patients having both a defined clinical syndrome and genetic lesion. The rationale for this approach was that there would be clinical value to providing a systematic analysis of data according to both genetic and clinical classifications. However, for overall prevalence estimates, each patient was counted only once. We did not perform a risk of bias assessment because the included studies were uncontrolled cross-sectional studies without an identified intervention.

\section{Statistical analysis}

The proportion of patients with abnormal tests was summarized with a random effects meta-analysis, ${ }^{6}$ with the estimate of heterogeneity being taken from the inverse-variance. To account for studies with no outcomes of interest, i.e., zero events, an arcsine transformation was applied. ${ }^{7}$ Heterogeneity was assessed using the I-squared statistic.

\section{Data availability}

All data pertaining to this work (list of abstracts, articles reviewed, data entry spreadsheet, and statistical analysis) will be made available upon request by any qualified investigator.

\section{Results}

We identified 8,601 articles in our literature search for title and abstract review for relevance. After the primary screen, we retained 171 articles for full-text review. After assessing these studies for eligibility, 21 studies were included in our metaanalysis. The Preferred Reporting Items for Systematic Reviews and Meta-Analyses flowchart is presented in figure $1 .{ }^{8}$ The basic characteristics of the included studies are presented in table 1.

\section{ECG}

In our review, 14 studies provided data on ECG findings in adult patients. The overall prevalence of abnormalities was 0.39 (95\% confidence interval [CI]: 0.28-0.50) (figure 2). The data indicate a significantly higher prevalence of ECG abnormalities in patients with the m.3243A $>G$ mutation ( 0.65 [CI: 0.33-0.92]) compared with the m.8344A $>\mathrm{G}$ mutation (0.26 [CI: 0.10-0.46]), single mtDNA deletions (CI: 0.21 [0.13-0.305]), other mtDNA point mutations (0.21 [CI: $0.09-0.35])$, and nuclear gene mutations (0.13 [CI: 0.02-0.29]). However, the data for several of these groups originate predominantly from a single study. ${ }^{9}$ When analyzed by clinical syndrome, patients with MELAS had significantly more ECG abnormalities (0.88 [CI: 0.71-0.99]) than patients with CPEO (0.32 [CI: 0.17-0.49]) or other phenotypes ( 0.17
[CI: 0.00-0.49]). Given the heterogeneity in outcome reporting, it was not possible to perform analysis of specific ECG abnormalities with the exception of bundle branch block (BBB), which is presented in figure e-1 (links.lww.com/NXG/ A159). This abnormality was seldom reported in MM populations, and the overall prevalence was zero in many studies.

A total of 9 articles included ECG findings in pediatric patients (figure 3). We cannot conclude that there is any significant difference between syndromes because of the small number of reported participants. The overall prevalence of ECG abnormalities was 0.55 [CI: $0.38-0.71$ ]. We observed descriptively that abnormalities in $\mathrm{m} .3243 \mathrm{~A}>\mathrm{G}$ patients $(0.79$ [CI: 0.48-1.00]) were higher than detected in other genetic or phenotypic categories. In comparison to adults, pediatric patients with MM had a higher prevalence of ECG abnormalities (0.55 [CI: 0.38-0.71] compared with 0.39 [CI: $0.28-0.50]$ ), as a descriptive finding, which did not achieve statistical significance $(p=0.07)$.

\section{Echocardiography}

Fourteen of the included studies provided data on echocardiography findings in adult patients. The overall prevalence of abnormalities was calculated as 0.29 (CI: 0.17-0.42) (figure 4). The best-studied group was patients with the m.3243A $>\mathrm{G}$ mutation, in which data from 246 participants were reported. Here, it was expected that $m .3243 \mathrm{~A}>\mathrm{G}$ and $\mathrm{m} .8344 \mathrm{~A}>\mathrm{G}$ would be associated with a higher prevalence of abnormalities than other genetic defects. This was supported by the data when m.3243A $>\mathrm{G}$ and m.8344A>G (0.41 (CI: 0.21-0.62) and 0.44 (CI: 0.23-0.66)) were compared with single mtDNA deletions (0.05 [CI: 0.01-0.12]), other mtDNA point mutations (0.08 [CI: 0.01-0.20]), and nuclear gene mutations (0.00 [CI: $0.00-0.07])$. When analyzed by clinical syndrome, MELAS (0.80 [CI: 0.57-0.97]) had a higher prevalence compared with $\mathrm{CPEO}$ and other phenotypes. It was possible to perform an analysis for left ventricular hypertrophy ( $\mathrm{LVH})$, which had a prevalence of 0.53 in patients with MELAS (CI: 0.25-0.80) and a prevalence of 0.18 (CI: 0.10-0.27) in patients with MM overall (figure e-2, links.lww.com/NXG/A159).

Echocardiogram findings in child patients were reported in a total of 9 studies. The overall prevalence of abnormalities was 0.35 (CI: 0.23-0.47) (figure 5). There were no significant differences in prevalence between the syndromes or genotypes, although the data consisted of a small number of patients and originated from a small number of studies. Between pediatric and adult patients, there was no difference in the overall prevalence of abnormalities.

\section{Cardiac MRI}

CMRI was performed in adult patients in 5 studies, and there was substantial heterogeneity in the results. Meta-analyzing all 5 studies revealed an overall prevalence of abnormalities of 0.35 (CI: 0.09-0.66), but given the small number of participants and studies, it is difficult to draw any further conclusions (figure e-3, links.lww.com/NXG/A159). Only one 


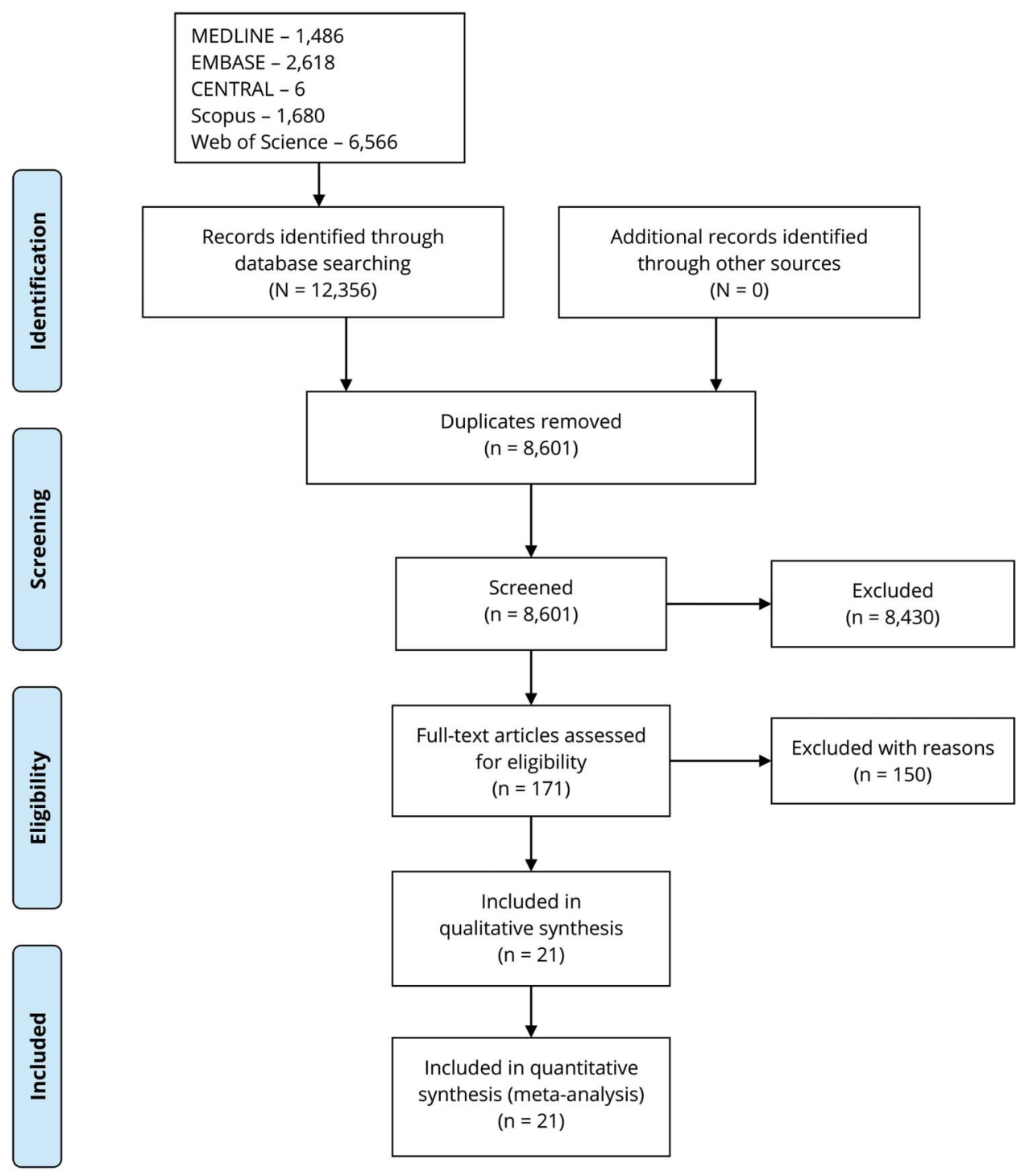

PRISMA = Preferred Reporting Items for Systematic Reviews and MetaAnalyses. study reported CMRI results in children, ${ }^{10}$ with data from only a single participant.

\section{Holter}

Holter monitoring was assessed in adults in only 4 studies ${ }^{5,10-12}$ with very low diagnostic yield and with an overall prevalence estimate for abnormalities of 0.03 (CI: 0.00-0.14) (figure e-4, links.lww.com/NXG/A159). This suggests that Holter monitor is a low-yield investigation for adult patients. Only one study included Holter monitor data from children. ${ }^{10}$

Common ECG and echo abnormalities were found in several studies of patients with various MM mutations and clinical syndromes, but they were unsuitable for meta-analysis, given the sparsity of the data. They are presented additively in table e-1 (links.lww.com/NXG/A159). These data provide an overall view of the diversity of findings in these common MM syndromes. Overall, the most severe cardiac abnormalities, such as LVH and ventricular pre-excitation abnormalities, were most prevalent in $\mathrm{m} .3243 \mathrm{~A}>\mathrm{G}$ or MELAS patients.

\section{Discussion}

Overall, patients with MM have a high prevalence of cardiac abnormalities, although the data indicate that MELAS has a higher prevalence of ECG abnormalities compared with other clinical syndromes, and the m.3243A $>\mathrm{G}$ mutation is associated with a higher prevalence of ECG abnormalities than other genetic defects. Abnormalities detected by echo are more prevalent in MELAS and myoclonic epilepsy with ragged red fibres (MERRF) compared with other syndromes, and when analyzed by genetic category, the $\mathrm{m} .3243 \mathrm{~A}>\mathrm{G}$ and $\mathrm{m} .8344 \mathrm{~A}>\mathrm{G}$ mutations were associated with a higher prevalence than other mutations. Comparing children to adult patients, we report the descriptive finding of a higher prevalence of ECG abnormalities in children compared with adults with MM, supporting the 
Table 1 Characteristics of included studies

\begin{tabular}{|c|c|c|c|c|c|c|c|}
\hline Author, year & PMID & $\begin{array}{l}\text { Cohort } \\
\text { type }\end{array}$ & $\begin{array}{l}\text { Cardiac modalities } \\
\text { studied }\end{array}$ & $\begin{array}{l}\text { Total participants } \\
\text { included }\end{array}$ & $\begin{array}{l}\text { Mean age of } \\
\text { participants }(y)\end{array}$ & $\begin{array}{l}\text { Age } \\
\text { range (y) }\end{array}$ & $\begin{array}{l}\text { Sex } \\
\text { (M:F) }\end{array}$ \\
\hline Akaike et al. $1997^{22}$ & 9068909 & Adult & ECG, echo & 5 & 48.0 & $20-64$ & $2: 3$ \\
\hline Anan et al. $1995^{35}$ & 7850981 & $\begin{array}{l}\text { Child, } \\
\text { adult }\end{array}$ & ECG, echo & 15 & 41.0 & $12-54$ & $9: 6$ \\
\hline Baik et al. $2010^{19}$ & 21189931 & Child & ECG & 57 & 4.8 & NA & $26: 31$ \\
\hline Baik et al. $2012^{20}$ & 23038991 & Child & ECG, echo & 27 & 5.0 & NA & $11: 16$ \\
\hline $\begin{array}{l}\text { Catteruicca et al. } \\
2015^{10}\end{array}$ & 25559684 & $\begin{array}{l}\text { Child, } \\
\text { adult }\end{array}$ & $\begin{array}{l}\text { ECG, echo, Holter, cardiac } \\
\text { MRI (CMRI) }\end{array}$ & 15 & 46.0 & $8-71$ & $5: 10$ \\
\hline $\begin{array}{l}\text { Cordeiro et al. } \\
2009^{18}\end{array}$ & 24209401 & Child & Echo & 63 & 0.77 & $0.17-1.37$ & $30: 33$ \\
\hline Florian et al. $2015^{17}$ & 26001801 & Adult & ECG, CMRI & 64 & 46.7 & $35-65$ & $28: 36$ \\
\hline Galetta et al. $2014^{36}$ & 25139213 & Adult & ECG, echo & 20 & 55.3 & NA & $5: 15$ \\
\hline $\begin{array}{l}\text { Hollingsworth et al. } \\
2012^{15}\end{array}$ & 22513320 & Adult & ECG, echo, CMRI & 10 & 42.5 & $30-55$ & $5: 5$ \\
\hline Ikawa et al. $2007^{21}$ & 17280875 & $\begin{array}{l}\text { Child, } \\
\text { adult }\end{array}$ & ECG, echo, MIBI & 5 & 39.8 & $16-51$ & $2: 3$ \\
\hline $\begin{array}{l}\text { Limongelli et al. } \\
2010^{11}\end{array}$ & 20083621 & $\begin{array}{l}\text { Child, } \\
\text { adult }\end{array}$ & ECG, echo, Holter & 30 & 39.2 & $16-62$ & 13:17 \\
\hline $\begin{array}{l}\text { Lindroos et al. } \\
2016^{16}\end{array}$ & 26112752 & Adult & CMRI & 14 & 46.5 & $36.2-57$ & $4: 10$ \\
\hline Nesbitt et al. $2013^{24}$ & 23355809 & Adult & Echo & 129 & NA & $0.91-74$ & $50: 79$ \\
\hline $\begin{array}{l}\text { Okajima et al. } \\
1998^{27}\end{array}$ & 9875091 & $\begin{array}{l}\text { Child, } \\
\text { adult }\end{array}$ & ECG, echo & 11 & 16.5 & $6-23$ & $8: 3$ \\
\hline $\begin{array}{l}\text { Pfeffer and Mezei } \\
2012^{3}\end{array}$ & 22987704 & Adult & ECG, echo & 15 & 56.9 & $18-83$ & $8: 7$ \\
\hline $\begin{array}{l}\text { Ueno and Shiotani } \\
1999^{23}\end{array}$ & 10598894 & Adult & Echo & 10 & 48.6 & NA & $6: 4$ \\
\hline Vydt et al. $2007^{12}$ & 17223431 & Adult & ECG, echo, Holter & 12 & 35.0 & $18-57$ & $5: 7$ \\
\hline Wahbi et al. $2010^{5}$ & 20177121 & $\begin{array}{l}\text { Child, } \\
\text { adult }\end{array}$ & ECG, echo, Holter & 18 & 42.6 & $12-71$ & $8: 10$ \\
\hline Wahbi et al. $2015^{9}$ & 26224072 & Adult & ECG, echo & 272 & 44.0 & $28-58$ & $\begin{array}{l}115: \\
157\end{array}$ \\
\hline $\begin{array}{l}\text { Wortmann et al. } \\
2007^{28}\end{array}$ & 17407476 & Child & ECG, echo & 5 & 5.6 & $0-14$ & $3: 2$ \\
\hline Yilmaz et al. $2012^{4}$ & 22143423 & Adult & ECG, CMRI & 37 & NA & $45-61$ & $14: 23$ \\
\hline
\end{tabular}

Abbreviation: $\mathrm{NA}=$ not available.

concept that $\mathrm{MM}$ has a more severe cardiac phenotype in childhood compared with adult patients. However, this difference was not significant $(p=0.07)$, perhaps relating to the small number of participants in pediatric studies.

The majority of the available data are from ECG and echo and both modalities demonstrated a high prevalence of detected abnormalities. We expected that a higher prevalence of abnormalities would be detected with CMRI, given that CMRI is recognized as a structural imaging test with higher sensitivity and reproducibility. ${ }^{13,14}$ The available evidence shows similar diagnostic yield of CMRI in comparison with echo; however, the data are very heterogeneous and from a limited number of patients. In studies including m.3243A $>\mathrm{G}$ and/or MELAS patients, 2 studies ${ }^{15,16}$ reported no CMRI abnormalities, and 1 study ${ }^{17}$ reported CMRI abnormalities in nearly all patients. This discrepancy can hopefully be addressed in future research. One study of CMRI in 14 participants showed no structural abnormalities, but an overall reduction of myocardial glucose uptake, which may be a biomarker of interest for future study. ${ }^{16}$ Only a single study included CMRI data from a pediatric participant. ${ }^{10}$ Overall, CMRI has thus far had very limited study in MM, and further investigation will be required to understand the advantages and limitations of this modality in patients with MM. 
Figure 2 Prevalence of ECG abnormalities with ES $(95 \% \mathrm{CI})$ in adult participants

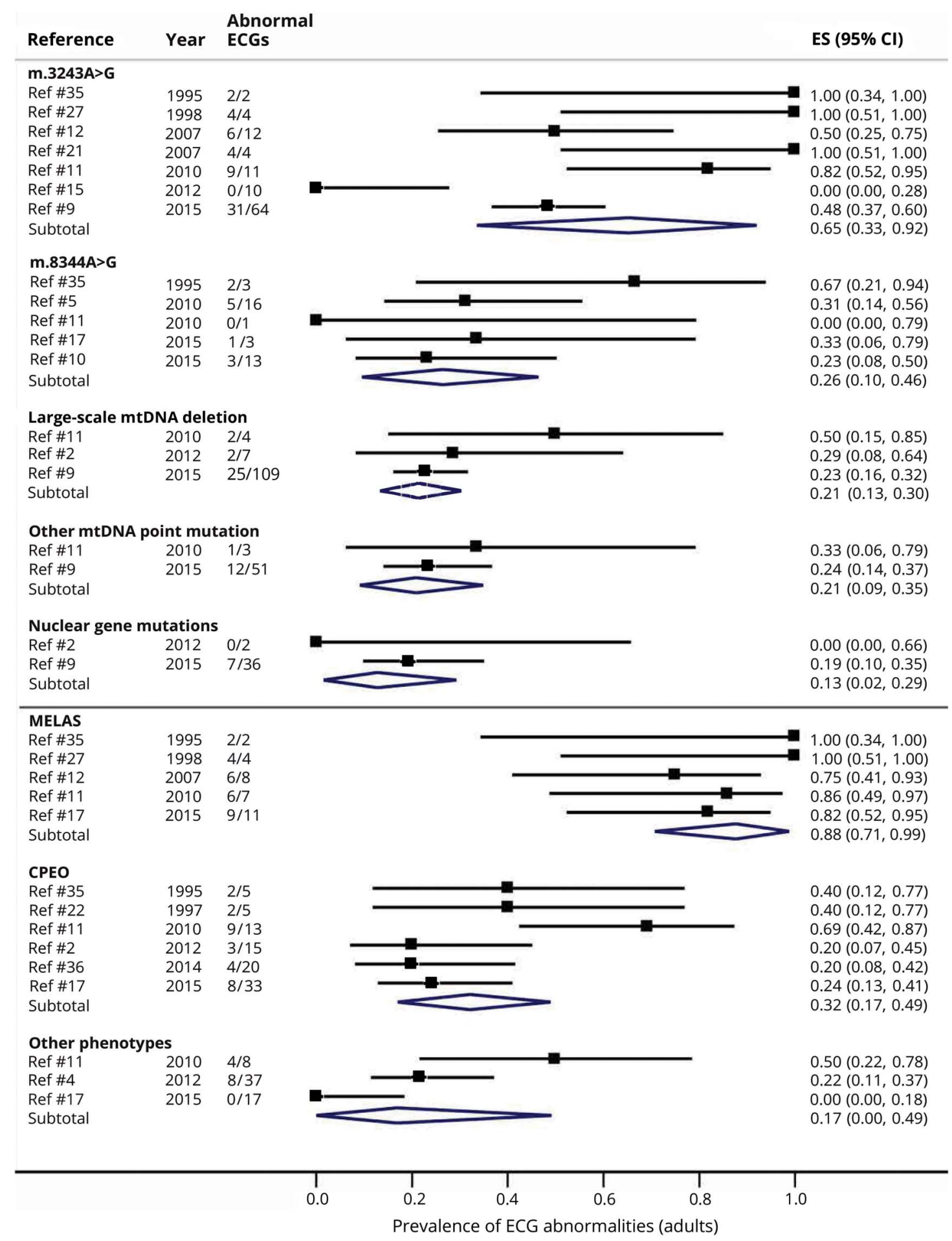

Note that patients are reported according to genetic defect (upper portion of the figure) and according to their clinical syndrome (lower portion of figure), and some patients may be duplicated if both a genetic defect and clinical syndrome was provided. This equally applies to figures 3-5. ES = effect size; $\mathrm{mtDNA}=$ mitochondrial DNA.

Pediatric patients may characteristically be considered to have a more severe phenotype than adult patients with MM. Based on this, it was expected that pediatric patients would have a higher prevalence of abnormalities, which was suggested by our data comparing ECG abnormalities in children and adults.
This suggests that pediatric patients with MM should be more closely monitored for cardiac conduction abnormalities. However, we cannot exclude the possibility that the prevalence of abnormalities for pediatric MM could have been inflated by the incidental inclusion of patients with KSS. 


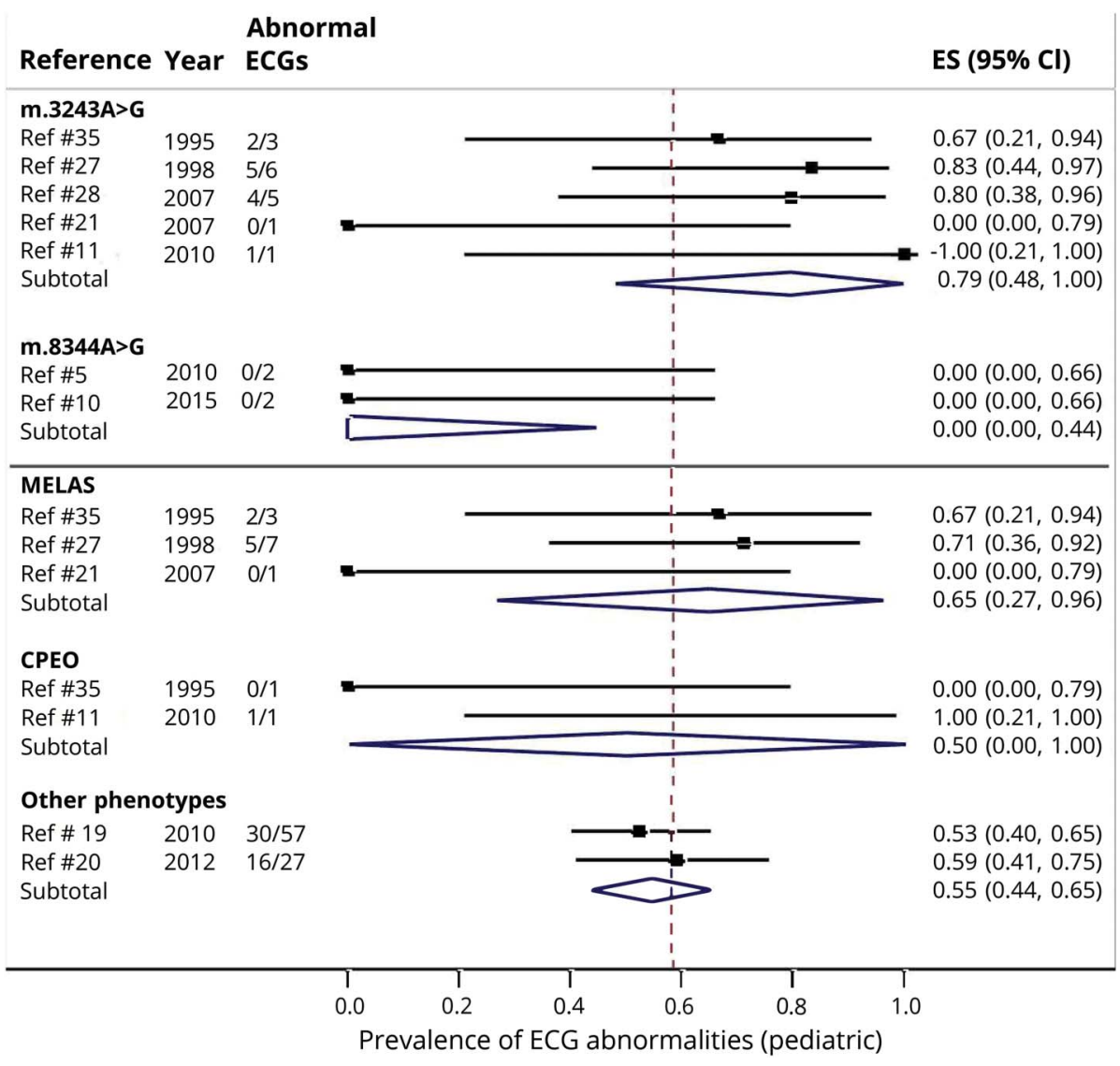

$E S=$ effect size

We observed that most studies of children included patients with nonspecific MM syndromes. ${ }^{18-20}$ Only 2 studies reported $\mathrm{m} .8344 \mathrm{~A}>\mathrm{G}$ patients, ${ }^{5,10}$ in which all patients had no abnormalities on ECG, but 1 patient had abnormalities detected by echo. ${ }^{10}$ Further investigation into pediatric MM patients, with better described clinical syndromes and molecular defects, should be conducted to determine the severity of the cardiac phenotype in these patients. In our analysis, Holter monitoring was a very low-yield investigation in adult and child patients with $\mathrm{MM}$, and its use as a routine screening procedure should perhaps be reassessed.

In our study, 10 articles described patients with MM with diabetes. ${ }^{9,11,12,15-17,21-24}$ Of the 122 patients with diabetes, 47 of them were diagnosed with MELAS. Given that diabetes is a major risk factor for cardiac dysfunction, it might be expected that patients with MELAS have greater cardiac risk as a consequence. This elevated risk was borne out by the data, and the interaction of diabetes on cardiac dysfunction in patients with MM is worthy of future study.

The goal of this study was to systematically review the prevalence of cardiac abnormalities in MM syndromes; it was not a goal of this work to characterize the natural history, symptoms, sudden-death occurrence, or therapies. However, these might be areas for future study, and in the course of this review, some of the included articles contained data regarding symptoms, sudden cardiac death, and natural history. We found 8 articles reporting symptoms of cardiac dysfunction in patients before diagnosis, including chest pain, ${ }^{4,11,17}$ various degrees of dyspnea, ${ }^{4,10,11,17,22}$ syncope, $^{11}$ palpitation ${ }^{10,11}$ and exercise limitations. ${ }^{11}$ Although 1 article found all patients to be asymptomatic, ${ }^{3} 5$ articles reported cardiac symptoms occurring before investigation for MM. ${ }^{9,11,17,21,25,26}$ One article ${ }^{9}$ reported 7 patients with a history of major adverse cardiac events including heart failure and third-degree atrioventricular block, whereas another study ${ }^{25}$ reported a patient who had previously underwent cardiac transplantation. Two studies ${ }^{21,26}$ presented patients with cardiomyopathy preceding their diagnosis of MM. Of interest, 1 study concluded that $31 \%$ of their patients with MM were previously diagnosed with cardiac conditions, particularly arrhythmia, impaired left ventricular systolic function, $\mathrm{LVH}$, coronary artery disease, and left bundle branch block. ${ }^{17}$ However, it is unclear in 1 study whether indicators of cardiac abnormalities were present before or after the diagnosis of $\mathrm{MM}^{22}$

An important limitation encountered in the literature is that few studies presented long-term follow-up data. Only 6 of the 21 included articles reported follow-up data regarding the 
Figure 4 Prevalence of echocardiography abnormalities with ES $(95 \% \mathrm{CI})$ in adult participants

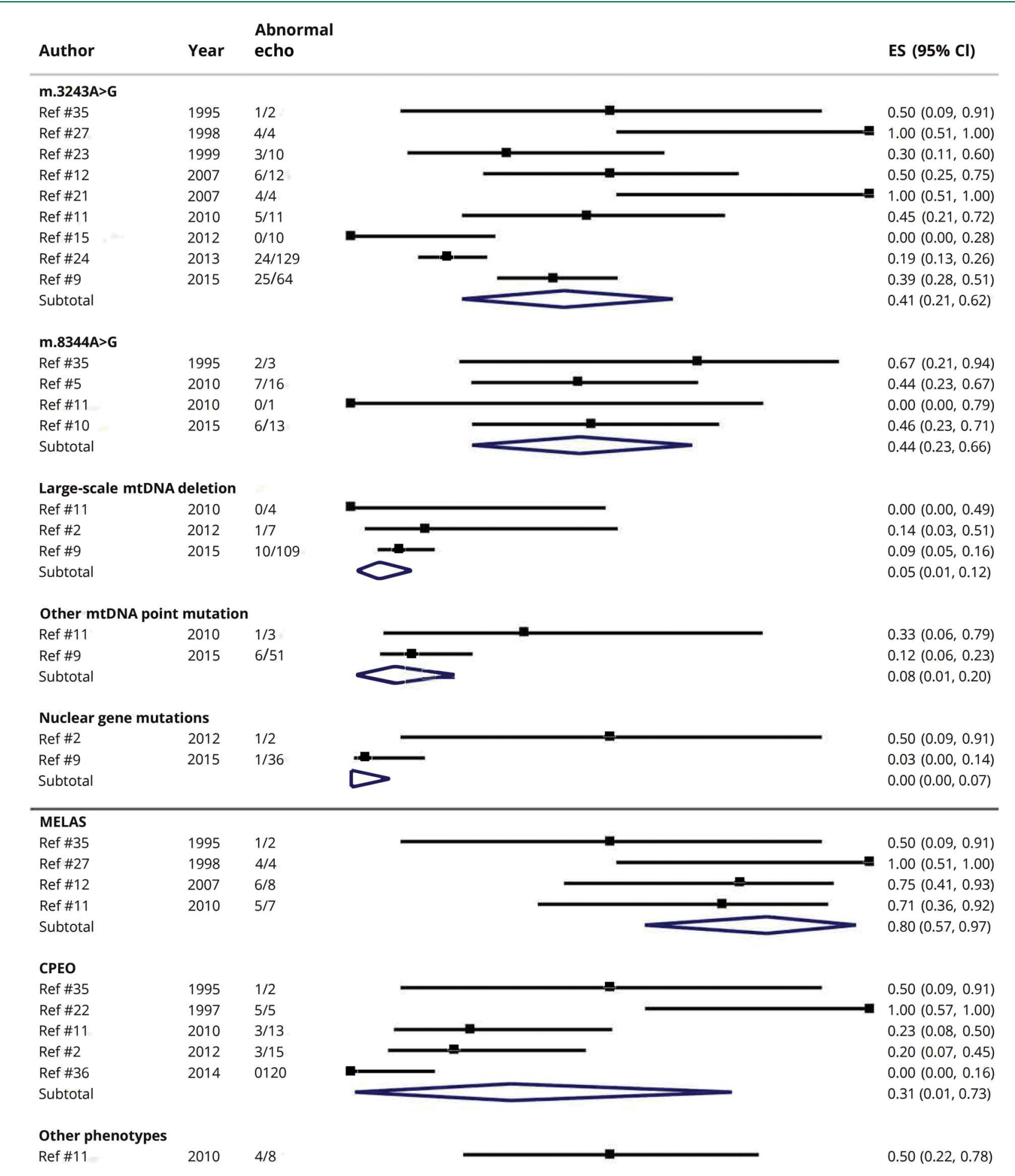

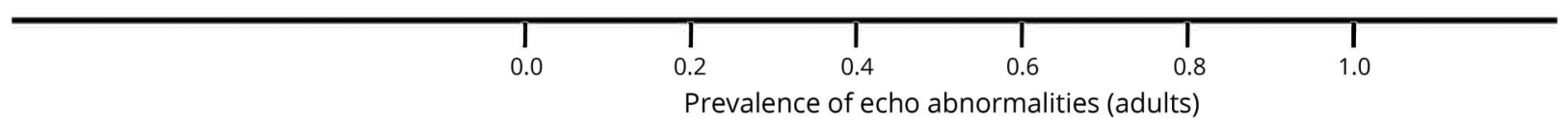

ES = effect size; $m$ tDNA = mitochondrial DNA. 


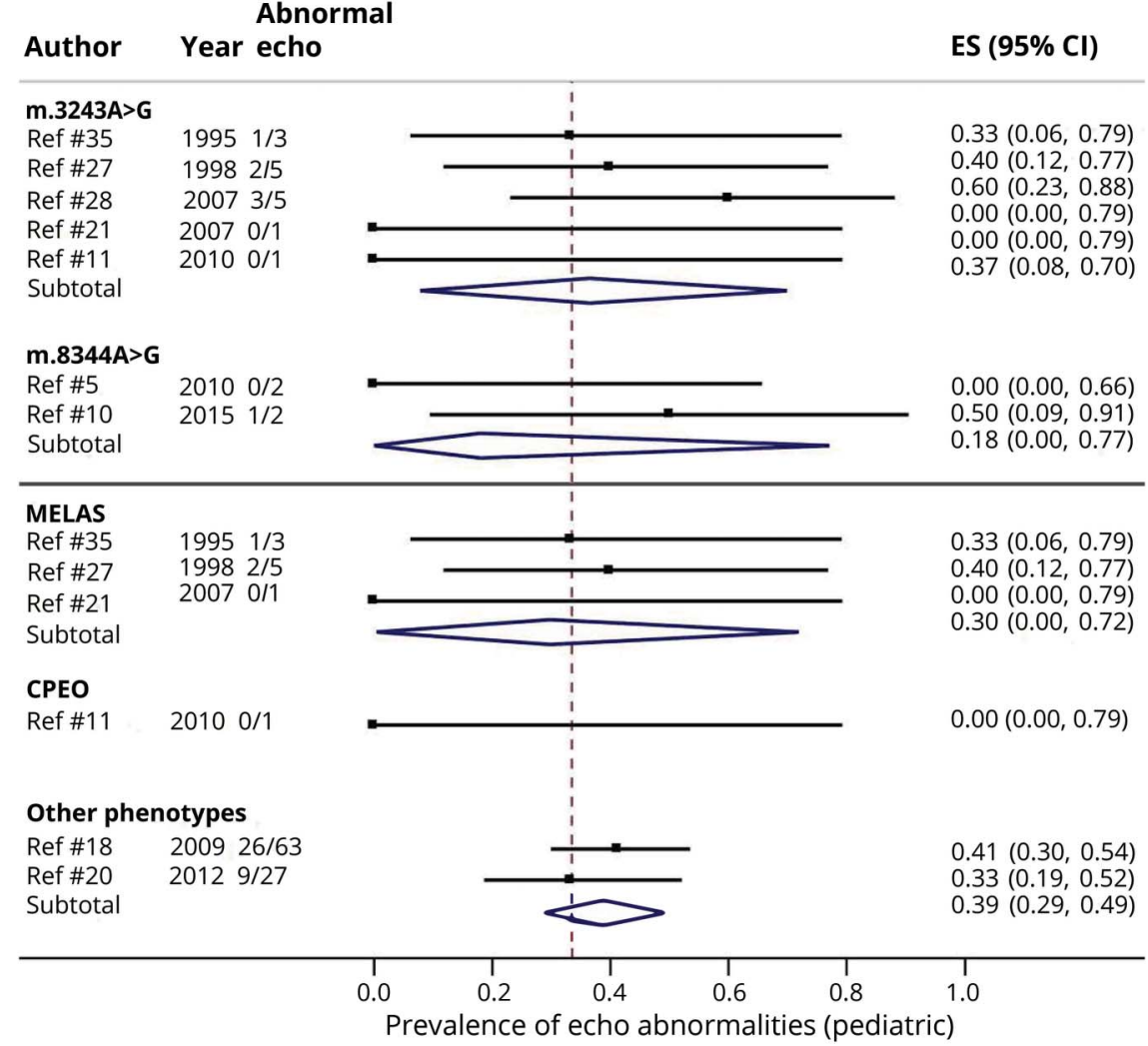

$E S=$ effect size evolution of cardiac dysfunction over time..$^{3,5,9,11,27,28}$ Five of these reported detailed follow-up data ${ }^{3,9,11,27,28}$ are as follows:

One study examined the occurrence of major cardiac events in a population of 260 patients, retrospectively followed for a median of 7 years. ${ }^{9}$ Twenty-seven of the patients died of cardiac events during the follow-up period, and the likelihood of death was associated with the presence of abnormalities on cardiac screening tests ( $42 \%$ in patients with 2 or more abnormalities on ECG/echo compared with $10 \%$ in the total study population). Patients with large-scale single mtDNA deletions and the m.3243A $>\mathrm{G}$ mutation had the most severe cardiac phenotype (although this former category may have incidentally included patients with KSS).

Another publication presented follow-up data on 15 patients diagnosed with adult-onset CPEO for a mean of 6.5 years with ECG and echo. ${ }^{3}$ A total of 5 patients developed new abnormalities, but in 4 of these cases, the abnormalities were unrelated to MM; only one patient developed a mild cardiomyopathy attributed to MM.

A previous investigation followed 32 patients for an average of 4.1 years, undergoing serial echocardiograms and clinical assessment. ${ }^{11}$ Two patients with initially normal ECG developed hypertrophic cardiomyopathy during follow-up. Serial echocardiography in a patient with CPEO and a patient with MM showed LVH development, whereas 1 patient with MELAS developed systolic impairment.

A study reported 6 pediatric m.3243A $>$ G patients, of which 2 died at an early stage of disease. ${ }^{28}$ One patient had died because of multiorgan failure, whereas the other had died because of cardiorespiratory failure. One patient had developed mild LVH and tricuspid regurgitation without pulmonary hypertension in the first year of follow-up. One patient had developed stroke-like episodes in adulthood. The remaining patients did not develop clinical symptoms of cardiac dysfunction over 3 years of follow-up.

Last, one study examined the development of cardiac dysfunction in adult and pediatric patients with MELAS (10 of 11 harbored the m.3243A $>\mathrm{G}$ mutation) during subsequent follow-up. ${ }^{27}$ They observed 11 patients, 4 adults, and 7 children, over an average time span of 6.9 years, whereas 6 patients were followed up for more than 5 years. Three patients showed a worsening ejection fraction, whereas 2 patients died, a child and an adult, one from causes unrelated to MM and the other due to congestive heart failure, respectively.

There are other works that did not meet our criteria for inclusion in this systematic analysis that have also provided important contributions to our understanding of the natural history of cardiac dysfunction in MM. A previous study of 228 
Table 2 Summary of findings from systematic review of the evidence

\begin{tabular}{ll}
\hline Principal screening tests & Recommendation \\
\hline Other screening tests requiring further study & $\begin{array}{l}\text { ECG } \\
\text { Echocardiography }\end{array}$ \\
\hline Recommended screening & Cardiac MRI (CMRI) \\
& $\begin{array}{l}\text { Available evidence did not allow for a specific recommendation, although we provide 2 general } \\
\text { recommendations: } \\
\text { In adults, patients with MELAS and MERRF should be screened more frequently than patients with } \\
\text { other syndromes } \\
\text { In patients with mitochondrial myopathy (MM), ECG screening should be more frequent for } \\
\text { children than adults }\end{array}$ \\
\hline Common abnormalities in CPEO & $\begin{array}{l}\text { Bundle branch block (BBB) } \\
\text { Left ventricular dysfunction }\end{array}$ \\
\hline Common abnormalities in $\mathbf{m . 3 2 4 3 A}>\mathbf{G}$ /MELAS and $>$ alMERRF & $\begin{array}{l}\text { Left ventricular hypertrophy (LVH) } \\
\text { Wolff-Parkinson-White syndrome (WPW) }\end{array}$ \\
\hline Areas for future study & $\begin{array}{l}\text { Natural history studies } \\
\text { Studies of treatment outcomes } \\
\text { Investigations of new modalities (CMRI and nuclear medicine), in comparison with established } \\
\text { modalities (ECG/echo) } \\
\text { Investigation into diabetes as a risk factor for cardiac dysfunction associated with MELAS and } \\
\text { possibly other mitochondrial diseases } \\
\text { Additional studies in pediatric patients }\end{array}$ \\
\hline
\end{tabular}

patients with single mtDNA deletion syndromes presented data from initial presentation and after an average of 18.7 years of follow-up. ${ }^{29}$ Over this time interval, the prevalence of cardiac conduction abnormalities increased from $1.3 \%$ to $5.3 \%$, and the prevalence of cardiomyopathy increased from $0 \%$ to $2.6 \%$. This demonstrates a lower prevalence of cardiac dysfunction than seen in our systematic analysis, which is a surprising finding given the inclusion of numerous KSS patients (which prevented it from being included in our systematic analysis). In contrast, another study of patients with MELAS and the m.3243A $>\mathrm{G}$ mutation had a mean follow-up of 3.8 years and identified death due to cardiac causes in 4 of 55 patients, which appears to be a more severe phenotype than expected for this short duration of follow-up. ${ }^{30}$ This high level of variability between publications emphasizes the need for further study of natural history after extended follow-up.

Based on the above data, the following observations are possible: (1) cardiac abnormalities are very common across various MM syndromes, (2) analysis of clinical syndromes indicates that MELAS and MERRF appear to have the most severe cardiac phenotype in adult patients, and (3) analysis of genetic subtypes reveals a more severe cardiac phenotype for the m.3243A $>\mathrm{G}$ and m.8344A $>\mathrm{G}$ mutations compared with other MM genetic defects. Cardiac screening investigations should be made on a case-by-case basis, but the following suggestions based on the evidence may be helpful and are summarized in table 2. ECG and echo are the best-established screening tests for MM; the role for CMRI requires further investigation. Generally, patients with MELAS and MERRF are considered to be at a higher risk of cardiac complications, and annual screening has been recommended. ${ }^{31}$ A common and well-described cardiac complication is Wolff-ParkinsonWhite syndrome (WPW), which is overrepresented in
MELAS. ${ }^{32}$ In contrast, adult-onset CPEO is generally considered to have a milder phenotype, and a previous study has suggested a screening interval as long as $3-5$ years. ${ }^{3}$ The results of our analysis appear to be consistent with these recommendations, but it should be emphasized that the data are based on a small number of studies, and the prevalence of abnormalities is high for most syndromes.

Some cardiac findings that have been associated with MM were rarely or not identified in this systematic analysis. Left ventricular noncompaction has been associated with several mtDNA point mutations, ${ }^{31,33}$ and we identified a single case with a mtDNA point mutation at position m.11232. ${ }^{11}$ Restrictive or histiocytoid cardiomyopathies have also been associated with $\mathrm{MM}^{34}$ but these were also not identified as part of this analysis. This was likely due to the inclusion criteria for this review, which excluded individual case reports and small case series.

Limitations of this review relate to the heterogeneity in study design, ascertainment methods, cardiac investigations, and outcome reporting. The majority of included publications were case series focused on cardiologic issues, which may have biased the reported cases toward a higher prevalence of cardiac involvement. The majority of the data pertain to patients with mtDNA-related diseases, and patients with nuclear mitochondrial disorders were not well represented. Details regarding the genetic investigations, which were performed (specific assays, their sensitivity, and other negative genetic investigations), were not generally reported. Details regarding muscle pathology interpretation were not generally reported, but our assumption was that a statement regarding diagnostic muscle pathology would be reliable in the reported literature. In 2 studies, ${ }^{4,17}$ data from patients with CPEO were 
aggregated with data from a few patients with Kearns-Sayre Syndrome (KSS), so it is possible that the prevalence of cardiac abnormalities was inflated by the incidental inclusion of some patients with KSS to the CPEO group (given that patients with KSS necessarily have cardiac conduction defects as part of their syndrome). In some of the studies including patients with the m.3243A $>\mathrm{G}$ mutation, data from mutation carriers who were asymptomatic or paucisymptomatic were included, which could also have affected the results. ${ }^{9,12,15,24}$ This illustrates another limitation of our study that patients with the m.3243A $>\mathrm{G}$ mutation included aggregate data from patients with MELAS syndrome or other phenotypes, which does not provide an accurate picture of the cardiac findings in phenotypic subgroups with the m.3243A $>\mathrm{G}$ mutation. A similar limitation is present for patients with the m.8344A $>\mathrm{G}$ mutation, in which only a subset would have had MERRF syndrome. There may also have been some overlap in the groups (for example, CPEO could overlap with single largescale $\mathrm{mtDNA}$ deletions, $\mathrm{mtDNA}$ point mutations, and nuclear gene mutation groups); based on the available information, the groups were assigned based on how they had been designated in their respective publications. Based on this classification, it is also possible that differences in the definition of each syndrome existed between the included publications, which is also a limitation of this study. In 1 article, it was necessary to assume which abnormalities were from ECG (BBB and WPW) compared with Holter monitor (ventricular dysrhythmias). ${ }^{10}$ In 1 article studying CMRI, only aggregate data were presented, but as this was in the normal range, we assumed a normal result for all patients. ${ }^{15}$ Finally, our analysis could not assess the severity of individual reported results, so even if the prevalence of results was similar between syndromes, we cannot rule out the possibility that some of the abnormalities may have been more severe in some syndromes than others.

This systematic analysis provides evidence to support a more aggressive cardiac screening for subsets of patients with MM, based on a more severe cardiac phenotype for MELAS and MERRF among clinical syndromes and a more severe phenotype for $\mathrm{m} .3243 \mathrm{~A}>\mathrm{G}$ and $\mathrm{m} .8344 \mathrm{~A}>\mathrm{G}$ mutations among genetic defects. We also report a descriptive finding of more prevalent ECG abnormalities in pediatric MM compared with adult MM. The prevalence of abnormalities with Holter monitoring is low and suggests that it may not be necessary for routine screening. More research is needed to determine how CMRI compares with echo as a modality for structural cardiac imaging. There are overall limited data on natural history and treatment response, and further longitudinal study of these conditions will be of benefit to the field. Further study including pediatric participants would also be of benefit, given the small numbers of studies and participants identified in this review.

\section{Acknowledgment}

The authors specially thank University of Calgary libraries and Theresa Connolly for their assistance with this review. They also thank Dr Ali Yilmaz and Dr. Karim Wahbi who provided additional information regarding their published data for this review.

\section{Study funding}

Asfia Quadir is the recipient of O'Brien Centre Summer Student Awards in 2017 and 2018.

\section{Disclosure}

Disclosures available: Neurology.org/NG.

\section{Publication history}

Received by Neurology: Genetics November 2, 2018. Accepted in final form April 30, 2019.

\section{Appendix Authors}

\begin{tabular}{|c|c|c|c|}
\hline Name & Location & Role & Contribution \\
\hline Asfia Quadir & $\begin{array}{l}\text { University of } \\
\text { Calgary, } \\
\text { Calgary, } \\
\text { Alberta, } \\
\text { Canada }\end{array}$ & First author & $\begin{array}{l}\text { Data collection, } \\
\text { data } \\
\text { interpretation, and } \\
\text { drafting and } \\
\text { editing of the } \\
\text { manuscript for } \\
\text { intellectual } \\
\text { content }\end{array}$ \\
\hline $\begin{array}{l}\text { Carly Sabine } \\
\text { Pontifex, } \\
\text { BSc }\end{array}$ & $\begin{array}{l}\text { University of } \\
\text { Calgary, } \\
\text { Calgary, } \\
\text { Alberta, } \\
\text { Canada }\end{array}$ & Author & $\begin{array}{l}\text { Data collection, } \\
\text { data } \\
\text { interpretation, and } \\
\text { editing of the } \\
\text { manuscript for } \\
\text { intellectual } \\
\text { content }\end{array}$ \\
\hline $\begin{array}{l}\text { Helen Lee } \\
\text { Robertson, } \\
\text { MLIS }\end{array}$ & $\begin{array}{l}\text { University of } \\
\text { Calgary, } \\
\text { Calgary, } \\
\text { Alberta, } \\
\text { Canada }\end{array}$ & Author & $\begin{array}{l}\text { Development of } \\
\text { search strategy } \\
\text { and editing of the } \\
\text { manuscript for } \\
\text { intellectual } \\
\text { content }\end{array}$ \\
\hline $\begin{array}{l}\text { Christopher } \\
\text { Labos, MD, } \\
\text { MSc }\end{array}$ & $\begin{array}{l}\text { Queen } \\
\text { Elizabeth } \\
\text { Health } \\
\text { Complex, } \\
\text { Montreal, } \\
\text { Quebec, } \\
\text { Canada }\end{array}$ & Author & $\begin{array}{l}\text { Statistical analysis, } \\
\text { data } \\
\text { interpretation, and } \\
\text { editing of the } \\
\text { manuscript for } \\
\text { intellectual } \\
\text { content }\end{array}$ \\
\hline $\begin{array}{l}\text { Gerald } \\
\text { Pfeffer, MD, } \\
\text { PhD }\end{array}$ & $\begin{array}{l}\text { University of } \\
\text { Calgary, } \\
\text { Calgary, } \\
\text { Alberta, } \\
\text { Canada }\end{array}$ & $\begin{array}{l}\text { Corresponding } \\
\text { author }\end{array}$ & $\begin{array}{l}\text { Design and } \\
\text { conceptualization } \\
\text { of the study, data } \\
\text { collection, data } \\
\text { interpretation, and } \\
\text { drafting and } \\
\text { editing of the } \\
\text { manuscript for } \\
\text { intellectual } \\
\text { content }\end{array}$ \\
\hline
\end{tabular}

\section{References}

1. Meyers DE, Basha HI, Koenig MK. Mitochondrial cardiomyopathy: pathophysiology, diagnosis, and management. Texas Heart Inst J 2013;40:385-394.

2. Pfeffer G, Chinnery PF. Diagnosis and treatment of mitochondrial myopathies. Ann Med 2013;45:4-16.

3. Pfeffer G, Mezei MM. Cardiac screening investigations in adult-onset progressive external ophthalmoplegia patients. Muscle Nerve 2012;46:593-596. 
4. Yilmaz A, Gdynia H-J, Ponfick M, et al. Cardiovascular magnetic resonance imaging (CMR) reveals characteristic pattern of myocardial damage in patients with mitochondrial myopathy. Clin Res Cardiol 2012;101:255-261.

5. Wahbi K, Larue S, Jardel C, et al. Cardiac involvement is frequent in patients with the m.8344A $>$ G mutation of mitochondrial DNA. Neurology 2010;74:674-677.

6. DerSimonian R, Laird N. Meta-analysis in clinical trials. Control Clin Trials 1986;7: 177-188.

7. Rucker G, Schwarzer G, Carpenter J, Olkin I. Why add anything to nothing? The arcsine difference as a measure of treatment effect in meta-analysis with zero cells. Stat Med 2009;28:721-738.

8. Moher D, Liberati A, Tetzlaff J, Altman DG; PRISMA Group. Preferred reporting items for systematic reviews and meta-analyses: the PRISMA statement. Ann Intern Med 2009;151:264-269.

9. Wahbi K, Bougouin W, Behin A, et al. Long-term cardiac prognosis and risk stratification in 260 adults presenting with mitochondrial diseases. Eur Heart J 2015;36: 2886-2893.

10. Catteruccia M, Sauchelli D, Della Marca G, et al. "Myo-cardiomyopathy" is commonly associated with the A8344G "MERRF" mutation. J Neurol 2015;262:701-710.

11. Limongelli G, Tome-Esteban M, Dejthevaporn C, Rahman S, Hanna MG, Elliott PM. Prevalence and natural history of heart disease in adults with primary mitochondrial respiratory chain disease. Eur J Heart Fail 2010;12:114-121.

12. Vydt TCG, de Coo RFM, Soliman OII, et al. Cardiac involvement in adults with m.3243A>G MELAS gene mutation. Am J Cardiol 2007;99:264-269.

13. Grothues F, Smith GC, Moon JC, et al. Comparison of interstudy reproducibility of cardiovascular magnetic resonance with two-dimensional echocardiography in normal subjects and in patients with heart failure or left ventricular hypertrophy. Am J Cardiol 2002;90:29-34.

14. Gardner BI, Bingham SE, Allen MR, Blatter DD, Anderson JL. Cardiac magnetic resonance versus transthoracic echocardiography for the assessment of cardiac volumes and regional function after myocardial infarction: an intrasubject comparison using simultaneous intrasubject recordings. Cardiovasc Ultrasound 2009;7:38.

15. Hollingsworth KG, Gorman GS, Trenell MI, et al. Cardiomyopathy is common in patients with the mitochondrial DNA m.3243A $>$ G mutation and correlates with mutation load. Neuromuscul Disord 2012;22:592-596.

16. Lindroos MM, Parkka JP, Taittonen MT, et al. Myocardial glucose uptake in patients with the m.3243A $>$ G mutation in mitochondrial DNA. J Inherit Metab Dis 2016;39:67-74.

17. Florian A, Ludwig A, Stubbe-Drager B, et al. Characteristic cardiac phenotypes are detected by cardiovascular magnetic resonance in patients with different clinical phenotypes and genotypes of mitochondrial myopathy. J Cardiovasc Magn Reson 2015;17:40.

18. Cordeiro M, Scaglia F, Lopes Da Silva S, et al. The brain-heart connection in mitochondrial respiratory chain diseases. Neuroradiol J 2009;22:558-563.

19. Baik R, Chae JH, Lee YM, Kang HC, Lee JS, Kim HD. Electrocardiography as an early cardiac screening test in children with mitochondrial disease. Korean J Pediatr 2010; 53:644-647.
20. Baik R, Yu R, Lee YM, Kang HC, Lee JS, Kim HD. Early cardiac evaluation in children with non-specific mitochondrial disease with isolated mitochondrial respiratory chain complex I defect. J Paediatr Child Health 2012;48:1016-1020.

21. Ikawa M, Kawai Y, Arakawa K, et al. Evaluation of respiratory chain failure in mitochondrial cardiomyopathy by assessments of $99 \mathrm{mTc}-\mathrm{MIBI}$ washout and $123 \mathrm{I}-$ BMIPP/99mTc-MIBI mismatch. Mitochondrion 2007;7:164-170.

22. Akaike M, Kawai H, Yokoi K, et al. Cardiac dysfunction in patients with chronic progressive external ophthalmoplegia. Clin Cardiol 1997;20:239-243.

23. Ueno $\mathrm{H}$, Shiotani $\mathrm{H}$. Cardiac abnormalities in diabetic patients with mutation in the mitochondrial tRNA(Leu(UUR)) gene. Jpn Circ J 1999;63:877-880.

24. Nesbitt V, Pitceathly RDS, Turnbull DM, et al. The UK MRC Mitochondrial Disease Patient Cohort Study: clinical phenotypes associated with the m.3243A $>$ G mutation-implications for diagnosis and management. J Neurol Neurosurg Psychiatry 2013;84:936-938.

25. Malfatti E, Laforet $P$, Jardel C, et al. High risk of severe cardiac adverse events in patients with mitochondrial m.3243A $>$ G mutation. Neurology 2013;80: $100-105$

26. Holmgren D, Wahlander H, Eriksson BO, Oldfors A, Holme E, Tulinius M. Cardiomyopathy in children with mitochondrial disease; clinical course and cardiological findings. Eur Heart J 2003;24:280-288.

27. Okajima Y, Tanabe Y, Takayanagi M, Aotsuka H. A follow up study of myocardial involvement in patients with mitochondrial encephalomyopathy, lactic acidosis, and stroke-like episodes (MELAS). Heart 1998;80:292-295.

28. Wortmann SB, Rodenburg RJ, Backx AP, Schmitt E, Smeitink JA, Morava E. Early cardiac involvement in children carrying the $\mathrm{A} 3243 \mathrm{G}$ mtDNA mutation. Acta Paediat 2007;96:450-451

29. Mancuso M, Orsucci D, Angelini C, et al. Redefining phenotypes associated with mitochondrial DNA single deletion. J Neurol 2015;262:1301-1309.

30. Kaufmann P, Engelstad K, Wei Y, et al. Natural history of MELAS associated with mitochondrial DNA m.3243A>G genotype. Neurology 2011;77:1965-1971.

31. Bates MG, Bourke JP, Giordano C, d'Amati G, Turnbull DM, Taylor RW. Cardiac involvement in mitochondrial DNA disease: clinical spectrum, diagnosis, and management. Eur Heart J 2012;33:3023-3033.

32. Sproule DM, Kaufmann P, Engelstad K, Starc TJ, Hordof AJ, De Vivo DC. WolffParkinson-White syndrome in patients with MELAS. Arch Neurol 2007;64: $1625-1627$.

33. Arbustini E, Favalli V, Narula N, Serio A, Grasso M. Left ventricular noncompaction: a distinct genetic cardiomyopathy? J Am Coll Cardiol 2016;68:949-966.

34. El-Hattab AW, Scaglia F. Mitochondrial cardiomyopathies. Front Cardiovasc Med 2016;3:25.

35. Anan R, Nakagawa M, Miyata M, et al. Cardiac involvement in mitochondrial diseases. A study on 17 patients with documented mitochondrial DNA defects. Circulation 1995;91:955-961.

36. Galetta F, Franzoni F, Mancuso M, et al. Cardiac involvement in chronic progressive external ophthalmoplegia. J Neurol Sci 2014;345:189-192. 


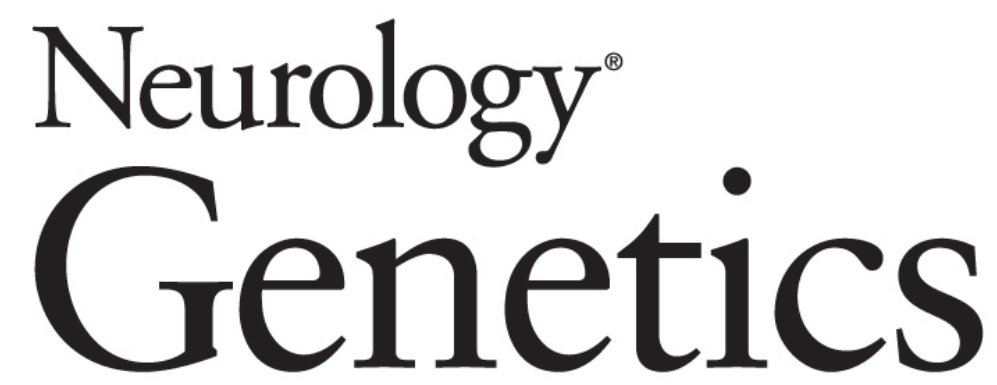
Systematic review and meta-analysis of cardiac involvement in mitochondrial myopathy
Asfia Quadir, Carly Sabine Pontifex, Helen Lee Robertson, et al.
Neurol Genet 2019;5;
DOI 10.1212/NXG.0000000000000339

This information is current as of June 12, 2019

Neurol Genet is an official journal of the American Academy of Neurology. Published since April 2015, it is an open-access, online-only, continuous publication journal. Copyright Copyright $\odot 2019$ The Author(s). Published by Wolters Kluwer Health, Inc. on behalf of the American Academy of Neurology.. All rights reserved. Online ISSN: 2376-7839.

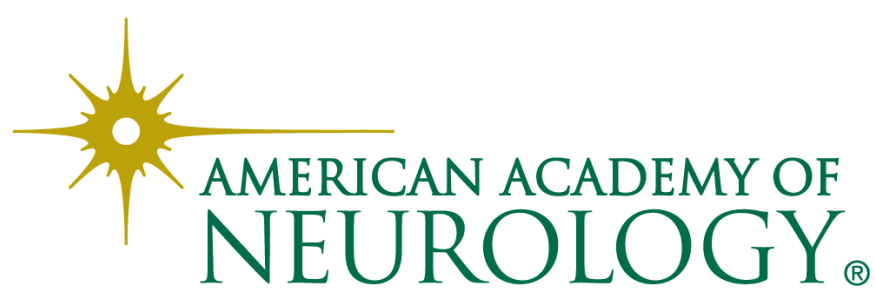




\section{Updated Information \& Services}

References

Citations

Subspecialty Collections

Permissions \& Licensing

Reprints including high resolution figures, can be found at: http://ng.neurology.org/content/5/4/e339.full.html

This article cites 36 articles, 4 of which you can access for free at: http://ng.neurology.org/content/5/4/e339.full.html\#\#ref-list-1

This article has been cited by 1 HighWire-hosted articles: http://ng.neurology.org/content/5/4/e339.full.html\#\#otherarticles

This article, along with others on similar topics, appears in the following collection(s):

\section{Cardiac}

http://ng.neurology.org//cgi/collection/cardiac

Mitochondrial disorders

http://ng.neurology.org//cgi/collection/mitochondrial_disorders Mitochondrial disorders; see Genetics/Mitochondrial disorders http://ng.neurology.org//cgi/collection/mitochondrial_disorders_see_ge netics-mitochondrial_disorders

Muscle disease

http://ng.neurology.org//cgi/collection/muscle_disease

Information about reproducing this article in parts (figures,tables) or in its entirety can be found online at:

http://ng.neurology.org/misc/about.xhtml\#permissions

Information about ordering reprints can be found online: http://ng.neurology.org/misc/addir.xhtml\#reprintsus

Neurol Genet is an official journal of the American Academy of Neurology. Published since April 2015, it is an open-access, online-only, continuous publication journal. Copyright Copyright () 2019 The Author(s). Published by Wolters Kluwer Health, Inc. on behalf of the American Academy of Neurology.. All rights reserved. Online ISSN: 2376-7839.

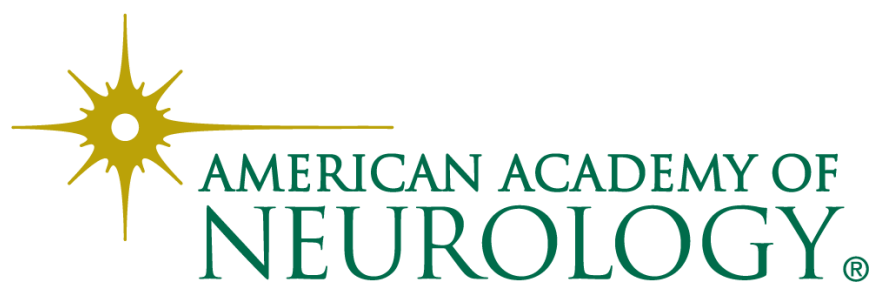

